\title{
O SENSORIAMENTO REMOTO COMO TÉCNICA AUXILIAR NOS ESTUDOS GEOLÓGICOS DA REGIÃO DE ALTO GRAU METAMÓRFICO DE IPIAÚ-BAHIA
}

\author{
J.B.Arcanjo ${ }^{1}$; J.S.F.Barbosa ${ }^{2}$; F.C.Alves da Silva ${ }^{3}$
}

PALAVRAS-CHAVES: Sensores remotos, granulitos, petrografia, corpos máficosultramáficos

ARCANJO, J.B. et al. (1996) O sensoriamento remoto como técnica auxiliar nos estudos geológicos da regiăo de alto grau metamórfico de Ipiaú-Bahia. Bol,IG-USP, Série Científica, 27:99-118.

\section{RESUMO}

A Folha de Ipiaú, situada na Regiäo Granulítica do Sul da Bahia, foi objeto de trabalhos de sensoriamento remoto, seguido de reconhecimento de campo e estudos petrograficos. Isto permitiu a elaboraçăo de um mapa geológico na escala 1:100.000.

A partir da análise fotogeológica e estudos de campo, a área estudada foi dividida em três dominios: (i) Dominio da Costa Atlântica compreendendo a parte leste da área, sendo formado por metatonalitos/trondhjemitos, metagabros, faixas de supracrustais intercaladas, além de corpos dispersos de ultramafitos e charnockitos; (ii) Domínio de Ipiaú, na parte central da área, sendo formado por ortognaisses graniticos/granodioriticos/tonalíticos com bandas de anfibolitos subordinadas além dos corpos graniticos de Itajibá e Dário Meira e, (iii) Dominio Jequié-Mutuipe, situado na porçăo NW da área sendo litologicamente representado por rochas charnockíticas e charnoenderbíticas. $O$ primeiro e terceiro Domínios estão equilibrados na fácies granulito enquanto o segundo é da fácies anfibolito alto.

Estes três dominios foram afetados no minimo por duas fases de deformação dúctil, que imprimiram nas litologias uma estrutura gnaíssica típica. Admite-se que a primeira fase (F1) represente uma tectônica de baixo ângulo cujas evidências foram quase que completamente mascaradas pelo evento subsequiente. A fase (F2) desenvolveu dobras apertadas a isoclinais com planos axiais subverticais. Nas zonas de deformação mais intensa, esta fase evoluiu até transposiçăo incluindo um componente de cisalhamento transcorrente sinistral, que colocou lado a lado, níveis crustais de profundidades variadas e blocos de rochas de naturezas diferentes. O metamorfismo granulítico é de idade transamazônica e contemporâneo às duas fases tectônicas.

Finalmente deve-se ressaltar que a interpretação de diferentes produtos de sensoriamento remoto, seguida de checagem de campo, permitiu identificar os corpos máficos-ultramáficos de Mirabela, Floresta e Palestina, portadores de mineralizaçðes, que penetraram em sítios extensionais ligados à etapa final do evento (F2). Estes sitios estruturais merecem, portanto, estudos de maior detalhe, do ponto de vista da prospeção mineral.

\footnotetext{
'CPRM - Companhia de Pesquisa de Recursos Minerais, Salvador, Bahia, Brasil.

${ }^{2}$ Aluno Pós-Graduando, IG/UFBA.

${ }^{3}$ Aluno Pós-Graduando, IG/UFBA.
} 


\section{ABSTRACT}

The Ipiaú region located in the High Grade Metamorphic Province of southern Bahia, Brazil has been investigated by means of geologic photointerpretation using aerial photographs, Radar and satellite imagery, followed by field reconnaissance and petrographic studies. These activities resulted in a 1:100,000 scale geologic map and the identification of a several favourable sites for mineral prospecting.

The data led to divide the area into three main domains: (i) The Atlantic Coast, in the eastern portion, is composed essentially of metatonalites and trondhjemites with metagabbro intercalations, supracrustal rocks and occasional pyroxenite and charnockite bodies; (ii) The Ipiau, the central domains of the area, is represented by granitic/granodioritic/tonalitic orthogneisses with subordinate amphibolite bands, as well as typical granites, such as those of Itajibá and Dário Meira, and (iii) The Jequie-Mutuipe in the northwestern part of the area which is basically composed of charnockites with subordinate charno-enderbites. The lithologies of the first and latter domains were metamorphosed up to the granulites facies, whereas the second is in the amphibolite facies.

Two main ductile deformational regional events took place in the area. We suggest that the first phase (F1) could represent low-angle tectonics, most of those evidence was erased by the second phase (F2). The last event generated tight to isoclinal folds with subvertical axial planes. This phase evolved to transposition and included a strike-slip component. Kinematic criteria indicate leftlateral movement. The associated granulitic metamorphism is of Transamazonic age.

Finally, it should be emphasized that this study also identified the structural setting of mafic/ultramafic bodies that bear prospected to PGE and sulfides. This fact lead to new perspectives related to prospection of such mineralizations not only in this area but all along the granulitic belt of southeast Bahia.

\section{INTRODUÇÃO}

Os dados aqui apresentados são oriundos de trabalho de sensoriamento remoto sistemático, trabalhos de campo e estudos petrográficos desenvolvidos numa área de cerca de $12.300 \mathrm{~km}^{2}$ denominada região de Ipiaú, sudeste da Bahia (Fig. 1). A aplicação de sensoriamento remoto constou da interpretação de fotografias aéreas pancromáticas $1: 60.000$ e $1: 108.000$, bem como imagens multiespectrais TM-Landsat e de Radar (RADAMBRASIL), ambas em papel. Esta pesquisa teve como finalidade principal verificar a eficácia da utilização dos produtos de sensores remotos na cartografia geológica básica de áreas de alto grau metamórfico.

A região de Ipiaú situa-se a sudoeste da cidade de Salvador (Fig. 1) e geologicamente encontra-se inserida na denominada Região Granulítica do Sudeste da Bahia (Barbosa, 1986), cujas rochas se estendem numa faixa contínua, desde o sul do Estado da Bahia,

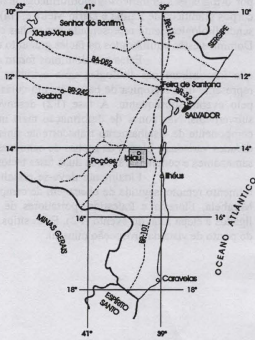

Figura 1 - Situaçăo geográfica da regiåo de Ipiaú. 
até o vale do rio Curaçá, ao norte (Fig. 2). Esta tem sido localmente pesquisada nos últimos anos, sobretudo em função da presença de corpos máficos - ultramáficos com indícios de mineralizações de sulfetos de metais de base e platina, como são os casos, das Fazendas Mirabela (Cunha \& Fróes, 1992; Abram \& Silva, 1992; Silva et al., 1992), Floresta e Palestina (Barbosa, 1995). Os estudos realizados por estes autores se concentraram essencialmente na delimitação, caracterização mineralógica e geoquímica desses corpos. A importância econômica destes "plutons" máficos-ultramáficos e a possível existência de outros corpos semelhantes, foram fatores adicionais que motivaram a realização do presente estudo.

Entre os trabalhos pioneiros sobre essas rochas de alto grau metamórfico da Região Granulítica do Sudeste da Bahia, pode-se citar os projetos de mapeamento geológico efetuados através do convênio DNPM - CPRM (Silva Filho et al., 1974; Pedreira et al., 1975), bem como o Projeto Aerogeofisico, Itaberaba-Belmonte (Canha, 1977) e o Projeto Levantamento Gravimétrico do Estado da Bahia (Gomes \& Motta 1980), os quais forneceram os primeiros dados geológicos da área. Também merecem destaque os estudos geocronológicos desenvolvidos por Cordani (1973), Cordani \& Iyer (1979), Costa \& Mascarenhas (1982) e Mascarenhas \& Garcia (1989), bem como aqueles que abordaram a petrografia das rochas da região. Entre esses últimos pode-se citar os de Sighinolfi $(1970,1971)$, Sighinolfi et al. (1981), Oliveira \& Lima (1982) e Oliveira et al. (1982). Os trabalhos geocronológicos permitiram identificar idades arqueanas e paleoproterozóicas na área, provavelmente ligadas aos ciclos geotectônicos Jequié e Transamazônico enquanto que, os trabalhos petrográficos possibilitaram definir a presença extensiva de rochas de alto grau, da fácies granulito, além de ainda estimar as condições de pressão e temperatura do metamorfismo regional. Entre as pesquisas voltadas para a ambiência geotectônica da área ressalta-se aquelas desenvolvidas por Mascarenhas (1973), Pedreira (1976), Almeida (1977), Inda \& Barbosa (1978), Siqueira (1978), Mascarenhas (1979), Figueira et al. (1979), Almeida (1981), Lima et al. (1981), Mascarenhas \& Sá (1982), Neves \& Souza (1984) e Mascarenhas et al. (1984), que definiram o denominado "Mobile Belt" da Costa Atlântica, considerado uma faixa de rochas de alto grau metamórfico, retrabalhada no paleoproterozóico, durante o Ciclo Transamazônico. Esta unidade geotectônica situa-se a leste do Complexo Jequié (Cordani, 1973), de idade arqueana.

Os trabalhos acima mencionados contribuíram consideravelmente no entendimento da geologia dessa faixa granulítica do Estado da Bahia. Entretanto, foram as pesquisas desenvolvidas a partir de 1986, que forneceram uma nova concepção de estudos para esses terrenos de alto grau. Com base sobretudo na petroquímica, foi possível identificar litotipos para e ortoderivados anteriormente dificeis de serem separados através do mapeamento geológico convencional, além da química mineral que tem possibilitado uma melhor definição das paragêneses plutônicas e/ou metamórficas com o estabelecimento mais apurado das condiçőes físicas de temperatura e pressão do metamorfismo que atingiu a região. Barbosa (1986), por exemplo, baseado sobretudo nas técnicas acima mencionadas, individualizou três importantes domínios geológicos/geotectônicos na região: o Domínio da Costa Atlântica a leste, o Dominio de Ipiaú na parte central e o Dominio Jequié-Mutuipe na parte oeste (Fig. 2).

Além disso, as pesquisas realizadas na última década, como aquelas 


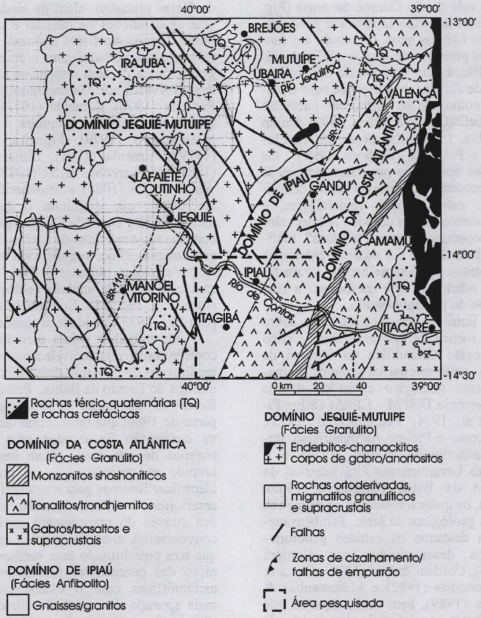

Figura 2 - Situaçăo geológica da regiāo de Ipiaú. Simplificado de Barbosa (1990).

de Barbosa (1988, 1989, 1991, 1992, 1995), Barbosa \& Fonteilles (1986, 1991), Wilson (1987), Wilson et al. (1988), Xavier et al. (1989), Figueiredo (1989), Cruz (1989), Sá \& Barbosa (1990), Conceição et al. (1991), Padilha et al. (1990), Gomes et al. (1991), Silva (1991), Arcanjo (1991), Martins \& Santos (1991), Aillon \& Barbosa (1992),
Marinho et al. (1992) e Arcanjo et al. (1992) tem permitido estabelecer parâmetros geológicos para a individualização das rochas pré-metamórficas e elaborar modelos geotectônicos e metalogenéticos mais adequados para a região. Assim, foi proposto um modelo no qual - Domínio da Costa Atlântica ou "Mobile Belt" da Costa Atlântica pas- 
sou a ser interpretado como um arco de ilha insular de idade paleoproterozóica; o Domínio de Ipiaú e arredores, uma bacia pós-arco e, o Domínio Jequié-Umtuipe ou Complexo Jequié, um provável ante-país de idade arqueana (Fig. 2). As rochas plutono-vulcânicas da bacia pósarco e grande parte daquelas que comporiam $\mathrm{o}$ arco insular foram obductadas sobre $o$ ante-pais, durante um período de colisão arco-continente. Isto teria provocado dobras deitadas de grandes extensões e com vergências para oeste compondo estruturas que são admitidas como formadas durante a primeira fase tectônica da região. Os depósitos de manganês, barita e outras ocorrências minerais ali encontrados, estão colocados de forma compatível dentro deste modelo geotectônico.

\section{SENSORIAMENTO REMOTO}

A observação de fotografias aéreas pancromáticas destes terrenos granulíticos da região de Ipiaú revela a existência de grandes alinhamentos, refletindo o elevado grau de estruturação tectônica de seus litotipos (Fig. 3). Esses alinhamentos mostram-se em geral anastomosados e quase sempre acompanhados por grande densidade de fotolineações, sugerindo a presença de zonas de cisalhamento. Estes lineamentos são notados sobretudo no setor sudeste da Folha. Nas imagens de Radar em papel (RADAMBRASIL) e TM-Landsat, bem como em fotos aéreas em diferentes escalas verifica-se também em áreas restritas, charneiras de dobras apertadas, rompidas em zonas de maior transposição.

$\mathrm{O}$ acidente geológico que mais se destaca nas fotos aéreas é uma ampla zona de cisalhamento com direção NNE, que é predominante na parte central da região (Figs. 3 e 4). A geometria sigmoidal da foliação sugere uma movimentação sinistral para a zona. Inse- ridos nela encontram-se os corpos de Mirabela, Floresta e Palestina, que se caracterizam nos produtos de sensores remotos pela ausência de elementos estruturais.

Por outro lado, a parte noroeste da área está caracterizada por grande densidade de fotolineações, bem como falhamentos longitudinais e fraturas perpendiculares (Figs. 3 e 4 ). Estes últimos elementos denotam o alto grau de fraturamento dos litotipos. O traçado linear desses falhamentos longitudinais, aliado aos fortes mergulhos verificados nos mesmos, são sugestivos de falhas transcorrentes, embora não tenha sido possivel diagnosticar, nas fotos, o sentido dos seus movimentos.

Assim, a partir da análise fotogeológica (Fig. 3) foi possível individualizar três segmentos crustais na área, separados por zonas de cizalhamento: um maior situado na parte leste, outro no centro da área e o terceiro, bem menor localizado na parte oeste (Fig. 4). Estes segmentos coincidem no campo com os Domínios da Costa Atlântica, Ipiaú e Jequié-Mutuipe (Barbosa, 1986, 1990), respectivamente de leste para oeste.

O segmento leste ou Domínio da Costa Atlântica parece ser composto essencialmente de granulitos exibindo "trends" preferencialmente na direção nordeste. Este segmento é caracterizado por um relevo rebaixado/arrasado, onde se destacam cristas alinhadas, portando tropia moderada a alta, correspondendo a corpos quartzíticos e rochas supracrustais associadas. O elevado grau de estruturação destas últimas fornece grande densidade de traços estruturais, possibilitando interpretar-se o sentido do mergulho destes litotipos. Os corpos máficos - ultramáficos, ovalados/circulares, como os das fazendas Mirabela, Floresta e Palestina situam-se neste segmento. Estes apresentam-se bem definidos na imagem de Radar (Fig. 3) através de um relevo forte, homogêneo 


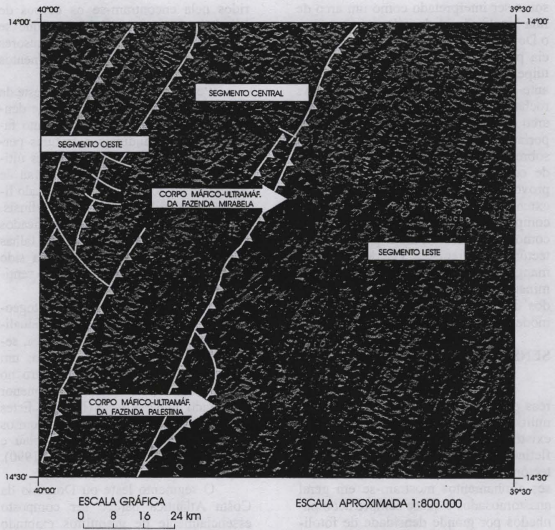

Figura 3 - Imagem de Radar (RADAMBRASIL) da regiăo de Ipiaú mostrando suas principais feições fotogeológicas.

e sem elementos estruturais visíveis. Nas fotografias aéreas, tanto aquelas na escala 1:108.000 como aquelas na escala 1:60.000, verifica-se o contraste entre estes corpos plutônicos, isotrópicos, com as rochas granulíticas encaixantes que possuem relevo moderado e são bem orientadas. Essas evidências sugerem uma época de intrusão para os corpos em foco, tardi a pós-tectônicas ao evento Transamazônico. Outros corpos menores, com características semelhantes a estes, foram identificados na parte central da imagem para posterior coleta de informações em campo para verificação da interpretação.

O segmento central ou Domínio de Ipiaú exibe como principal característica nas imagens de Radar e fotos aéreas, a incidência de relevo formado por serras orientadas e vales profundos. As características fotogeológicas sugerem que ele seja composto dominantemente por gnaisses e granitóides, ocorrendo subsidiariamente, bandas mais escuras, alongadas na direção regional. Os gra- 


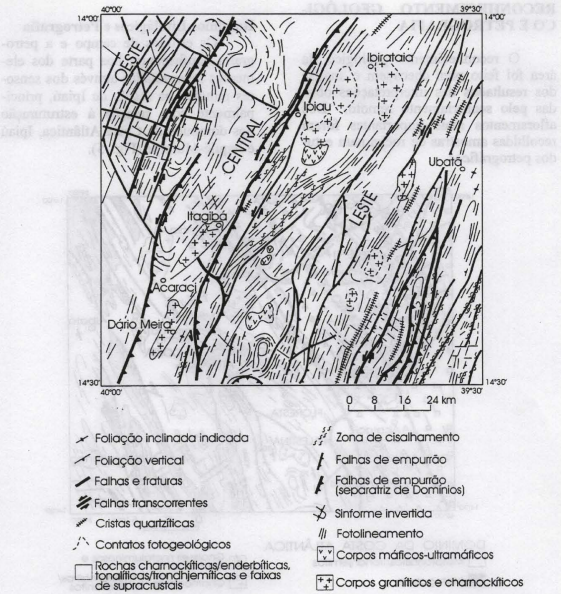

Figura 4 - Principais feiçōes fotointerpretadas dos terrenos de alto grau metamórfico da região de Ipiaú.

nitos de Itagibá e Dário Meira (Barbosa, 1995) estão introduzidos no limite leste deste segmento (Figs. 3 e 4).

O segmento oeste ou Domínio Jequié-Mutuipe apresenta-se morfologicamente definido através de um relevo homogêneo, bem mais expressivo que o segmento anterior, composto por um conjunto de serras orientadas NE-SW. Em geral os rios estão encaixados em vales profundos acompanhando o bandamento/foliação regional ou, mais restritamente, seguindo as falhas de direção NW, identificadas devido a deslocamentos das fotolineações. Os elementos texturais e estruturais bem como a presença marcante desses falhamentos transversais, constituem suas principais feições (Figs. 3 e 4). 


\section{RECONHECIMENTO GEOLÓGI- CO E PETROGRAFIA}

O reconhecimento geológico da área foi feito para checagem e análise dos resultados das interpretações obtidas pelo sensoriamento remoto. Dos afloramentos mais importantes foram recolhidas amostras de rocha para estudos petrográficos.

\section{Domínios Litológicos e Petrografia}

Os estudos de campo e a petrografia confirmaram boa parte dos elementos interpretados através dos sensores remotos na região de Ipiaú, principalmente com relação à estruturação dos domínios da Costa Atlântica, Ipiaú e Jequié-Mutuipe (Fig. 5).

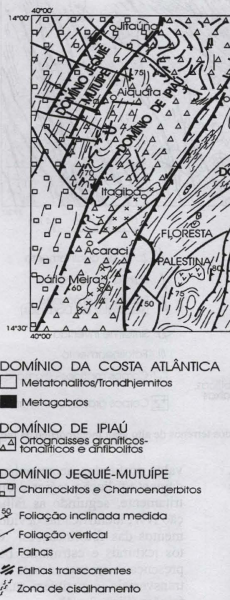

t Falhas de empurró

f Falhas de empumáo

* (separatiz de Dominios)

ऋ sinforme invertida

fil Lineamentos estruturais.

Figura 5 - Mapa geológico simplificado da região de Ipiaú. 


\section{Domínio da Costa Atlântica}

Este Domínio é composto predominantemente de metatonalitos/ trondhjemitos e metagabros subordinados, todos deformados e metamorfizados na fácies granulito. Exibem bandamento/foliação com atitudes em torno de N15E e mergulhos variando de $60^{\circ}$ a 80 para SE. Os metatonalitos/trondhjemitos (PR-66, PR-63, Tab. 1) são rochas de coloração verde acinzentada, relativamente homogêneas, com granulação grossa e textura milonítica, recristalizada, com bandamento composicional. Quando homogêneas, estas rochas são formadas basicamente por quartzo $\mathrm{e}$ plagioclásio. A confirmação de que estas rochas são metatonalitos/trondhjemitos tem sido feita com a utilização não só da microssonda eletrônica, que tem mostrado que o plagioclásio é o oligoclásio, mas também com a petroquimica de elementos maiores, traços e Terras Raras que têm confirmado neste Domínio a presença desses litotipos. Estes constituem uma seqüência magmática cálcio-alcalina de baixo potássio, semelhante àquelas que ocorrem em arcos de ilhas ou margem continental ativa (Barbosa \& Martin, em preparação). $\mathrm{O}$ ortopiroxênio, do tipo hiperstênio, também ocorre nestas rochas mas sempre em pequenas quantidades. Ainda são encontrados como minerais acessórios, o clinopiroxênio, do tipo salita, e o feldspato potássico pertítico mas, somente em poucas amostras. Minerais opacos são onipresentes, mas igualmente acessórios. A biotita é detectada, sendo formada pelo retrometamorfismo dos minerais ferro-magnesianos e opa$\cos$ (Tab. 1). Com relação aos metagabros (PR-68, PR-64, PR-69, PR-67, PR-65A, Tab. 1), estes ocorrem como bandas nas rochas anteriores, com espessuras que variam desde centimétri- cas a métricas (máximo de 5 metros). Mineralogicamente eles são constituídos por plagioclásio (bitownita/anortita), hiperstênio (enstatita) e clinopiroxênio (augita), tendo quartzo, opacos, apatita e zircão como acessórios (Barbosa et al., 1996) (Tab. 1). Algumas bandas desses metagabros contêm granada em quantidades apreciáveis. Hornblenda verde e biotita marrom aparecem freqüentemente, em relações texturais com os piroxênios e opacos que evidenciam um retrometamorfismo para a fácies anfibolito.

Os corpos das fazendas Palestina e Floresta foram caracterizados preliminarmente como piroxenitos (PR-72-C, PR-72A, PR-72B, Tab. 1). Estes são compostos predominantemente de orto e clinopiroxênio, ocorrendo o plagioclásio em infimas quantidades, como intercumulus. Os opacos estão constantemente presentes e a hornblenda, quando ocorre, é sempre secundária. Por sua vez, o corpo da Fazenda Mirabela foi estudado por Abram \& Silva (1992), tendo sido demonstrado que ele é composto de gabro-norito na zona de borda, de serpentinitos/dunitos e peridotitos na zona inferior, de piroxenitos na zona intermediária e de leucogabro/noritos na zona superior. Todos estes corpos estão praticamente indeformados e parcialmente reequilibrados na fácies granulito visto que ainda apresentam texturas e minerais ígneos preservados. Ainda com relação a estes "plutons" máficosultramáficos, a geotermometria indicou para dois deles temperaturas plutônicas acima de $1000^{\circ} \mathrm{C}$ e temperaturas de reequilibrio sub-solidus em torno de $850^{\circ} \mathrm{C}$ (Barbosa \& Sapucaia, 1996).

Dispersas e isoladas neste Dominio encontram-se faixas de rochas supracrustais granulitizadas. As cristas identificadas nas imagens dos sensores remotos são de fato quartzitos, os quais em geral estão associados a gnaisses 


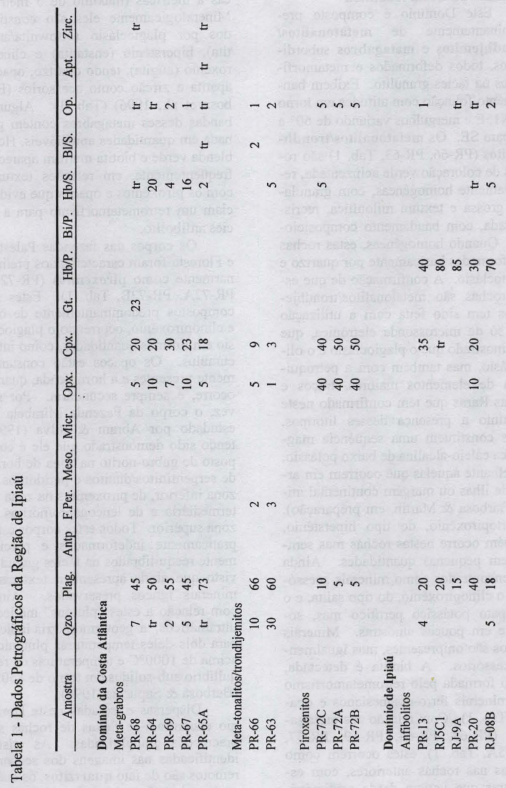




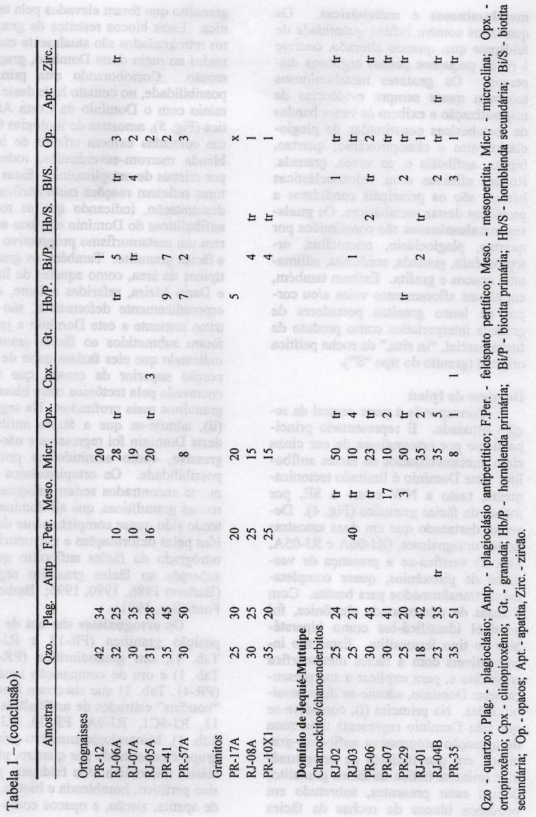


metaluminosos e metabásicas. Os quartzitos contêm ínfima quantidade de feldspato que, quando alterado, confere à rocha pequenos pontos argilosos dispersos. Os gnaisses metaluminosos mostram quase sempre evidências de migmatização e exibem às vezes bandas de metabásicas constituídas de plagioclásio, orto e clinopiroxênio, quartzo, biotita, anfibólio e, às vezes, granada. Rochas efusivas e/ou vulcanoclásticas básicas são os principais candidatos a protólitos destas metabásicas. Os gnaisses metaluminosos são constituídos por quartzo, plagioclásio, microclina, ortopiroxênio, granada, cordierita, sillimanita, opacos e grafita. Exibem também, em alguns afloramentos veios e/ou corpos de leuco granitos portadores de granada interpretados como produto da fusão parcial, "in situ," da rocha pelítica original (granito do tipo "S").

\section{Domínio de Ipiaú}

Corresponde à parte central da região estudada. É representado principalmente por ortognaisses de cor cinza clara, metamorfizados na fácies anfibolito. Este Domínio é limitado tectonicamente, tanto a NW como a SE, por rochas da fácies granulito (Fig. 4). Deve ser destacado que em duas amostras desses ortognaisses, (RJ-06A e RJ-05A, Tab. 1) verifica-se a presença de vestígios de piroxênios, quase completamente transformados para bastita. Com a ajuda da microssonda eletrônica, foi possível identificá-los como hiperstênios do tipo ferrossilita. Estes são incompativeis com a fácies metamórfica anfibolito e, para explicar a sua presença neste Domínio, admite-se duas possibilidades. Na primeira (i), considera-se que este Domínio representa uma zona de transição progressiva anfibolito-granulito, em que indícios de ortopiroxênios (mineral índice da fácies granulito) podem estar presentes, sobretudo em pequenos blocos de rochas da fácies granulito que foram elevados pela tectônica. Estes blocos restritos de granulitos retrogradados são atualmente encontrados no meio deste Domínio, graças à erosão. Corroborando esta primeira possibilidade, no contato leste deste Domínio com o Domínio da Costa Atlântica (Fig. 5), amostras de litologias básicas coletadas exibem cristais de hornblenda marrom-esverdeados, rodeados por cristais de ortopiroxênio. Estas texturas refletem reações metamórficas de desidratação, indicando que as rochas anfibolíticas do Domínio em foco sofreram um metamorfismo progressivo para a fácies granulito. Também, os granitos típicos da área, como aqueles de Itajibá e Dario Meira, referidos adiante, estão esporadicamente deformados, são restritos somente a este Domínio e jamais foram submetidos ao fácies granulito, indicando que eles faziam parte de uma porção superior da crosta, que ficou encravada pela tectônica entre blocos de granulitos mais profundos. $\mathrm{Na}$ segunda (ii), admite-se que a fácies anfibolito deste Domínio foi regressiva e não progressiva, como admitido na primeira possibilidade. Os ortopiroxênios raramente encontrados seriam relíquias das rochas granulíticas, que ali dominavam, tendo sido quase completamente destruidas pelas deformações e metamorfismo retrógrado da fácies anfibolito que se superpôs ao fácies granulito regional (Barbosa 1986, 1990, 1995; Barbosa \& Fonteilles, 1991).

Os ortognaisses são ora de composição granítica (PR-12 e RJ-07A, Tab. 1), ora granodioritica (PR-57A, Tab. 1) e ora de composição tonalítica (PR-41, Tab. 1) que encerram bandas e "boudins" estirados de anfibolitos (PR13, RJ-5C1, RJ-9A, PR-20, RJ-08B, Tab. 1). Mineralogicamente o primeiro grupo é constituído por quartzo, plagioclásio, microclina e/ou feldspato potássico pertítico, hornblenda e biotita, além de apatita, zircão, e opacos como aces- 
sórios. O segundo grupo é formado de quartzo, plagioclásio, microclina, hornblenda e biotita, com opacos e apatita em quantidades mínimas. $\mathrm{O}$ terceiro grupo é constituído por quartzo e plagioclásio, além de hornblenda, biotita e opacos. Os anfibolitos são compostos principalmente de plagioclásio (bitownita/anortita) e hornblenda verde, tendo os opacos como acessórios. Em algumas amostras, clinopiroxênio do tipo salita e quartzo ocorrem em pequena quantidade (Barbosa et al., 1996)(Tab. 1). Alguns corpos graníticos (PR-17A, RJ-08A, PR-10X1, Tab.1) estão introduzidos neste Domínio, podendo-se destacar, entre eles, os de Itajibá e Dário Meira (Fig. 5). Eles são facilmente separados dos ortognaisses encaixantes por sua cor rosa clara, granulação mais grossa e, quando atingidos pela deformação dúctil da região, são distinguidos pela presença de porfiroclastos de microclina e/ou feldspatos potássicos pertíticos imersos em uma matriz mais fina milonítica. Mineralogicamente, essas rochas graníticas são formadas de quartzo, plagioclásio, feldspato potássico pertítico, microclina, hornblenda, biotita e opacos (Tab. 1). Encraves dos ortognaisses encaixantes são encontrados principalmente na porção marginal destes "plutons".

\section{Domínio de Jequié-Mutuipe}

$\mathrm{Na}$ área de pesquisa o Domínio Jequié-Mutuipe é o menos extenso de todos (Fig. 5). O reconhecimento de campo e a petrografia mostraram que as serras elevadas, bem evidenciadas nos sensores, são constituídas por charnockitos e charnoenderbitos. São rochas relativamente homogêneas, de cor verde-acinzentada quando frescas, e branca-amarelada quando alteradas. Nestes casos permitem que se visualize melhor seu aspecto bandado/foliado e sua granulação grossa com porfiroclastos de feldspatos de dimensões centimétricas imersos em uma matriz de granulação média a fina, milonítica. São rochas dificeis de serem separadas no campo, sobretudo quando frescas. Entretanto, verifica-se que os charnoenderbitos, quando alterados, são ligeiramente mais bandados que os charnockitos. Mineralogicamente os charnockitos (RJ-02, RJ-03, PR-06, PR-29, RJ-04B, Tab. 1) são formados de quartzo, mesopertita, microclina, plagioclásio (andesina) e hiperstênio (ferrosilita). A hornblenda marrom e o clinopiroxênio (ferro-augita), sempre ocorrem em pouca quantidade (Barbosa et al., 1996). Anfibólio esverdeado e biotita têm expressão subordinada. Opacos e zircão são acessórios comuns. Ao microscópio, notase que os charnoenderbitos (PR-07, RJ-01, PR-35, Tab. 1) são formados de quartzo, plagioclásio e ortopiroxênio, sendo o clinopiroxênio mais abundante que nos charnockitos. Estudos recentes de química mineral têm demonstrado que o plagioclásio destas rochas é do tipo andesina; o ortopiroxênio é um hiperstênio com composição química próxima da ferrosilita e, a ferro-salita/ferroaugita o clinopiroxênio mais comum (Barbosa et al., 1996). Microclina e hornblenda são subordinadas, enquanto que a biotita parece ser mais retrógrada que ígnea. A bastita e a clorita também estão presentes como produtos de alteração retrógrada dos piroxênios, principalmente dos hiperstênios. Opacos, apatita e zircão são os minerais acessórios mais comuns (Tab. 1).

\section{GEOLOGIA ESTRUTURAL}

Os dados existentes permitem sugerir uma evolução estrutural da área através de dois eventos de deformação dúctil. Segundo dados gravimétricos (Gomes et al., 1991), zonas de cisalhamento da região tendem a se horizontalizar em profundidade sugerindo a existência de uma tectônica horizontal pre- 
coce. Este evento precoce (F1) é considerado como sendo responsável pela foliação/bandamento inicial das rochas, e está representado por pequenas estruturas que indicam transposição (i.e., "rootless folds"). Estas são observadas onde a foliação/bandamento ainda conserva baixo mergulho, sugerindo, também, uma tectônica de baixo ângulo para este evento (Alves da Silva et al., 1996).

O evento (F2), interpretado como de evolução progressiva ao evento (F1), gerou dobras apertadas de direção geral N10-20E com eixo b2 de baixo caimento e plano axial de mergulho forte, embora em alguns locais seja de apenas $50^{\circ}$, para sudeste. Este evento evoluiu até a transposição. Nestes planos subverticalizados do evento (F2), nota-se uma lineação mineral/estiramento subhorizontal de difícil visualização em grande parte dos afloramentos devido à recristalização dos minerais na fácies granulito. Os critérios cinemáticos encontrados (porfiroclástos, zona de pressão assimétrica, etc), sobretudo próximos às falhas de empurrão (Fig. 5), apontam para uma movimentação transcorrente sinistral, com componente cizalhante. A zona de cizalhamento existente na parte central da área investigada (Fig. 3), e que hospeda os principais corpos de rocha máfica-ultramáficas (p.e. Mirabela), está ligada às etapas finais deste evento (F2).

Falhas e fraturas, facilmente identificadas nas fotos aéreas, imagens de satélite e de Radar, representam a deformação rúptil da área. Em geral, três conjuntos de falhas/fraturas são identificados: (i) N70W; (ii) $\mathrm{N} 20 \mathrm{~W}$ e (iii) N70E. Todos os conjuntos mostram planos subverticalizados sendo o Terceiro, em termos de freqüência, o menos importante. Neste contexto não estão incluídas as fraturas subhorizontais provocadas por alívio de pressão.

Embora não existam estudos deta- lhados dos corpos graníticos de Itajibá e Dário Meira, as evidências existentes, tais como xenólitos das encaixantes já deformadas, heterogeneidade da deformação, levaram Alves da Silva et al. (1996) a postularem uma colocação tardia ao evento (F2).

A deformação e o metamorfismo concomitante são de idade transamazônica e considerados como provenientes de colisões de blocos que ocorreram em toda a região sudeste da Bahia (Wilson, 1987; Barbosa, 1990; Ledru et al., 1994). Estas colisões teriam provocado uma tectônica de baixo ângulo, com vergência para oeste, cujos vestígios estão preservados na área através das "rootless folds", do evento (F1), e encontradas em locais onde o bandamento/foliação ainda conserva baixo mergulho (Alves da Silva et al., 1996). Progressivamente e sob o efeito dos mesmos esforços foram geradas as dobras (F2), cuja etapa final produziu zonas de cisalhamentos e falhas de empurrão assinaladas nas Figuras 4 e 5 . Admite-se que foi esta tectônica transamazônica que colocou lado a lado níveis crustais de profundidades variadas e blocos de rochas de naturezas diferentes, como parece ser o caso dos três Domínios identificados na área.

\section{CONCLUSŌES}

As fotografias aéreas, imagens TM-Landsat e de Radar têm se mostrado muito úteis na cartografia geológica básica dos terrenos de alto grau metamórfico do Estado da Bahia. A região de Ipiaú é mais um exemplo deste fato, visto que os trabalhos de campo e estudos petrográficos realizados, comprovaram as interpretações realizadas através dos produtos dos sensores remotos.

Este trabalho permitiu subdividir a área em três domínios litológicos/ estruturais distintos, os quais confirmam 
aqueles definidos regionalmente por Barbosa (1986, 1990) denominados de Domínios da Costa Atlântica, Ipiaú e Jequié-Mutuipe (Fig. 5). O Domínio da Costa Atlântica, metamorfisado na fácies granulito, é formado principalmente por meta tonalitos/trondhjemitos com intercalações de bandas meta gabróicas de larguras e comprimentos variados e alguns corpos de charnockitos. Faixas de supracrustais (quartzitos, gnaisses metaluminosos e metabásicas) estão imbricadas tectonicamente nos metatonalitos/trondhjemitos. No Domínio de Ipiaú, metamorfisado na fácies anfibolito, ocorrem ortognaisses de composição granítica, granodiorítica e tonalítica, contendo bandas de anfibolitos subordinadas, além dos corpos de granitos de Itajibá e Dário Meira. Por sua vez, o Domínio Jequié-Mutuipe, metamorfisado na fácies granulito, composto basicamente de charnockitos e charnoenderbitos subordinados, é o de menor extensão na Folha de Ipiaú.

Com relação à tectônica, dois eventos deformacionais são propostos para a área. $\mathrm{O}$ evento (F1), ligado a uma tectônica horizontal, e o evento (F2). Este último mascara o anterior e desenvolve dobras apertadas que evoluiram até a transposição. Zonas de cisalhamento sinistrais e falhas de empurrão são associadas a este evento que, provavelmente, representa a fase final de amalgamação de blocos distintos. Vale ressaltar que não existem diferenças da evolução estrutural entre os três Dominios, sugerindo que os eventos deformacionais afetaram indistintamente toda a área.

Tanto os eventos de deformação (F1) e (F2) como o metamorfismo regional associado são considerados de idade transamazônica, do Paleoproterozóico (Wilson, 1987; Barbosa, 1990; Ledru et al., 1994). Assim, os principais elementos geológicos encontrados na área têm demonstrado que: (i) os três Domínios identificados na região são constituídos de litotipos distintos tendo sido justapostos pela tectônica transamazônica atuante na área, (ii) a colocação de corpos graníticos e máficos-ultramáficos ocorreu muito provavelmente na etapa final do evento (F2) e, desta forma, representam as rochas mais jovens da região, e (iii) em especial os corpos máficos-ultramáficos de Mirabela, Floresta e Palestina, com indícios de mineralização de sulfetos e platinoides, são corpos de forma ovala$\mathrm{da} /$ arredondada e parecem que penetraram em sítios extensionais ligados às etapas finais do evento (F2).

Finalmente ratifica-se a importância das formas de relevo, padrões de drenagem, tonalidade e textura das fotos aéreas não só na análise estrutural e na individualização de domínios litológi$\cos$, mas também na identificação de sítios propícios à colocação de corpos máficos-ultramáficos. Do ponto de vista econômico estas informações sugerem que a análise estrutural integrada com o sensoriamento remoto pode ser uma ferramenta útil nos trabalhos de prospecção, não somente nesta área, mas em toda Região Granulítica do Sudeste da Bahia.

\section{AGRADECIMENTOS}

Gostariamos de registrar nossos agradecimentos ao professor Abilio Carlos da Silva Pinto Bittencourt e ao geólogo Juracy de Freitas Mascarenhas pela leitura e correção do texto. Também ao $\mathrm{CNPq}$ somos agradecidos por ter fornecido os meios financeiros necessários para a realização desta pesquisa.

\section{REFERÊNCIAS BIBLIOGRÁFICAS}

ABRAM, M.B.; SILVA, M.G. (1992) O corpo máfico - ultramáfico da Fazenda Mirabela, Ipiaú - BA - Química 
Mineral, Litogeoquímica e Evolução Petrogenética. In: CONGRESSO BRASILEIRO DE GEOLOGIA, 37 . São Paulo, 1992. Boletim de Resumos Expandidos. São Paulo, SBG. v.1, p.449-450.

AILLON, M.P.; BARBOSA, J.S.F. (1992) As rochas metamórficas de alto grau da região de Cachoeira, São Felix e Cruz das Almas, Bahia. 1992. In: SIMPÓSIO REGIONAL DE GEOLOGIA BAHIA/SERGIPE, 1 ., Salvador, 1992. Anais. Salvador, SBG. v.1, p. 96-99.

ALMEIDA, F.F.M. (1977) O Cráton do São Francisco. Revista Brasileira de Geociências, v.7, p.349-364.

ALMEIDA, F.F.M. (1981) O Cráton do Paramirim e suas relações com o do São Francisco. In: SIMPÓSIO SOBRE O CRÁTON DO SÃO FRANCISCO E SUAS FAIXAS MARGINAIS, 1., Salvador, 1981. Anais. Salvador, SME/CPM. v.1, p.1-10.

ALVES DA SILVA, F.C.; BARBOSA, J.S.F.; DAMASCENO, J.A. (1996) Estilo deformacional das rochas de alto grau metamórfico da região de Ipiaú, SE da Bahia. In: CONGRESSO BRASILEIRO DE GEOLOGIA, 39., Salvador, 1996. Boletim de Resumos Expandidos. Salvador, SBG. v.6, p. 262-266.

ARCANJO, J.B.A. (1991) Programa Levantamentos Geológicos Básicos do Brasil : Itabuna Folha SD-24-YB-VI; Estado da Bahia: texto explicativo. Brasilia, DNPM. (Relatório não publicado)

ARCANJO, J.B.A.; BARBOSA, J.S.F.; OLIVEIRA, J.E. (1992) Caracterização petrográfica e metamórfica dos granulitos do Arqueano/Proterozóico Inferior da Região de Itabuna - Bahia. Revista Brasileira de Geociências, v.22, n.1, p.47-55.

BARBOSA, J.S.F. (1986) Constitution lithologique et metamorphique de la region granulitique du Sud de Bahia - Brésil. Paris, 401p. (Tese Doutorado) - Université Pierre et Marie Curie, França.

BARBOSA, J.S.F. (1988) Principais geobarômetros utilizados em granulitos. Análise dos resultados de um exemplo do sul da Bahia - Brasil. Revista Brasileira de Geociências, v. 18, n. 2, p. $162-169$.

BARBOSA, J.S.F. (1989) Química mineral utilizada na identificação das fácies metamórficas da região granulítica do Sul da Bahia - Brasil. Revista Brasileira de Geociências, v.19, n.3, p.350-366.

BARBOSA, J.S.F. (1990) The granulites of the Jequie Complex and Atlantic Coast Mobile Belt, Southern Bahia. An expression of Archean/Early Proterozoic plate convergence. In: VIELZEUF, D.; VI$\mathrm{DAL}, \mathrm{Ph}$. (eds.) Granulites and crustal evolution. Dordrecht, Klumer Academic. p.195-221.

BARBOSA, J.S.F. (1991) Projeto geologia e metalogenia do Domínio da Costa Atlântica da Região Granulítica do Sul da Bahia - Brasil. Salvador, SME/SGM/UFBA/PPPG. (Relatório não publicado).

BARBOSA, J.S.F. (1992) Modelos geotectônicos do sul da Bahia. In: SIMPÓSIO REGIONAL DE GEOLOGIA BAHIA/SERGIPE, 1., Salvador, 1992. Anais. Salvador, SBG. p. $92-95$.

BARBOSA, J.S.F. (1995) Petrologia e implicações metalogenéticas das rochas granulíticas do segmento Boa Nova - Itajibá, sudeste da Bahia. Salvador, UFBA/PPPG/ CBPM. 110p. (Relatório não publicado)

BARBOSA, J.S.F.; FONTEILLES, M. (1986) Examen critique des resultats fournis par certains barometres courament utilisés en terrains granulitiques: exemples des granulites de 
Bahia (Brésil) et du Massif de l'Agly (France). Bulletin de Mineralogie, v. 109, p.359-376.

BARBOSA, J.S.F.; FONTEILLES, M. (1991) O metamorfismo da região granulítica do Sul da Bahia - Brasil. Revista Brasileira de Geociências, v. 19, n.1, p.3-16.

BARBOSA, J.S.F.; SAPUCAIA, N.S. (1996) Os corpos máficos-ultramáficos da região de Ipiaú - Bahia e suas encaixantes granulitizadas.In: CONGRESSO BRASILEIRO DE GEOLOGIA, 39., Salvador, 1996. Anais. Salvador, SBG. v.6, p.279292.

BARBOSA, J.S.F.; ARCANJO, A.B.J.; ALVES DA SILVA, F.C.; PINHO, I.C.A.; OLIVEIRA, M.P.S.; SAVINI, D.S. (1996) Geologia das rochas de alto grau metamórfico da região de Ipiaú-sudeste da Bahia-Brasil. In: CONGRESSO BRASILEIRO DE GEOLOGIA, 39., Salvador, 1996. Anais. Salvador, SBG. v.6, p.272279.

BARBOSA, J.S.F.; MARTIN, H. (em preparação) Seqüências tonalíticastrondhjemíticas granulitizadas da parte central do Cinturão de Itabuna-Bahia-Brasil.

CANHA, R.P. (1977) Projeto Itaberaba - Belmonte - levantamento aeromagnetométrico e aerogamaespectrométrico. (Relatório não publicado)

CONCEIÇÃO, H.; BARBOSA, J.S.F.; AILLON, M.P. (1991) O Maciço sienítico de São Felix: petrologia e implicações geodinâmicas. In: CONGRESSO BRASILEIRO DE GEOQUIMICA, 3., São Paulo, 1991. Anais. São Paulo, SBGq. v.1, p.134138.

CORDANI, U.G. (1973) Evolução geológica precambriana da faixa costeira do Brasil entre Salvador e Vitória. Universidade de São Paulo. São Paulo, 98p. (Tese Livre-Docên- cia) - Instituto de Geociências, Universidade de São Paulo.

CORDANI, U.G.; IYER, S.S. (1979)

Geochronological investigation on the precambrian granulitic terrains of Bahia, Brazil. Precambrian Research, v.9, n. (3/4), p. 255-274.

COSTA, L.A.M; MASCARENHAS, J.F. (1982) The high - grade metamorphic terrains in the interval $\mathrm{Mu}-$ tuipe - Jequié, Archean - Central, Bahia. In: INTERNATIONAL SYMPOSIUM ON ARCHEAN AND EARLY PROTEROZOIC GEOLOGIC EVOLUTION AND METALOGENESIS ISAP, Salvador, 1982. Abstracts and Excursions. Salvador, SME. p.19-37.

CRUZ, M.J. (1989) Le massif du Rio Piau: une intrusion de nature gabbroique et anorthositique dans les terrains granulitiques du noyau Jequié - Bahia - Brésil. Paris, 280p. (Tese - Doutorado) - Université Pierre et Marie Curie, França.

CUNHA, J.C.; FROES, R.J.B. (1992) Complexo máfico - ultramáfico da Fazenda Mirabela: geologia e mineralização. In: CONGESSO BRASILEIRO DE GEOLOGIA, 37., São Paulo, 1992. Boletim Resumos Expandidos. São Paulo, SBG. v.2, p.158-159.

FIGUEIRA, E.P.; PEDREIRA, A.J.; GONCCALVES, J.C.V. (1979) Projeto integraçăo geológico - geofisica Itaberaba - Belmonte. Salvador, DNPM/CPRM. (Relatório Final).

FIGUEIREDO, M.C.H. (1989) Geochemical evolution of eastern Bahia, Brazil : a probable early proterozoic subduction - relation magmatic arc. Journal of South American Earth Sciences, v.2, p.131-145.

GOMES, R.A.A.D.; MOTTA, A.C. (1980) Projeto levantamento gravimétrico no Estado da Bahia. Salvador, DNPM/CPRM. 5v. (Relatório 
Final nåo publicado).

GOMES, R.A.A.D; ARCANJO, J.B.A.; SANTOS, R.A. (1991) Colisão de blocos com subducção na costa sul da Bahia. In: CONGRESSO DA SOCIEDADE BRASILEIRA DE GEOFÍSICA, 2., Salvador, 1991. Resumos Expandidos. Salvador, SBGf. v.1, p.154-159.

INDA, H.A.V; BARBOSA, J.S.F. (1978) Texto explicativo para o mapa geológico ao milionésimo do Estado da Bahia. Salvador, SME/ CPM. 122p.

LEDRU, P.; COCHERIE, A.; BARBOSA, J.S.F.; JOHAN, V.; NOSTOT, T. (1994) Ages du metamorphisme granulitique dans le craton du São Francisco (Brésil): implications sur la nature de l'orogène transamazonien. Comptes Rendus de la Academia Sciences. Paris. Serie II, v.318, p.251-257.

LIMA, M.I.C.; FONSECA, E.G.; OLIVEIRA, E.P. (1981) Geologia da folha de Salvador. In: PROJETO RADAM. Folha SD - 24, Salvador geologia, geomorfologia, pedologia, vegetação, uso potencial da terra. Rio de Janeiro, MME. (Levantamento de Recursos Naturais, 24)

MARINHO, M.M.; VIDAL, P.; ALIBERT, C.; BARBOSA, J.S.F.; ASBATÉ, P. (1992) Geochronology of the Jequié - Itabuna granulitic belt and Contendas - Mirante volcano sedimentary belt. In: PEDREIRA, A.J. (ed.). Petrologic and geochronologic evolution of the São Francisco Craton, Brazil. Salvador, CBPM/IGCP Project 280. 120 p.

MARTINS, A.A.M.; SANTOS, R.A. (1992) Programa Levantamentos Geológicos Básicos do Brasil, Ibicarai, Folha SD -24-Y- Estado da Bahia: texto Explicativo. Brasilia, DNPM, 1991. (Relatório não publicado)
MASCARENHAS, J.F. (1973) A geologia do centro leste do Estado da Bahia. In: CONGRESSO BRASILEIRO DE GEOLOGIA, 29., Aracajú, 1973. Resumo das Comunicações. Aracajú, SBG, p.35-66.

MASCARENHAS, J.F. (1979) Estruturas do tipo "Greenstone Belt" no leste da Bahia. In: INDA, H.A.V. (ed.) Geologia e recursos minerais do Estado da Bahia: textos básicos. Salvador, SME/CPM. v.2. p.25-53.

MASCARENHAS, J.F; GARCIA, T.W. (1989) Mapa geocronológico do Estado da Bahia, escala 1:1.000.000: texto explicativo. Salvador, SME/CPM. 188p.

MASCARENHAS, J.F; SÁ, J.H.S. (1982) Geological and metallogenic patterns in the Archean and Early Proterozoic of Bahia State, Eastern Brazil. Revista Brasileira de Geociências, v.13, n.2, p.193-214.

MASCARENHAS, J.F.; PEDREIRA, A.J.; MISI, A. (1984). Província São Francisco. In: ALMEIDA, F.F.M.; HASUI, Y. (eds.) O precambriano do Brasil. São Paulo, Edgard Blücher. p.46-122.

NEVES, J.P.; SOUZA, J.D. (1984) Projeto mapas metalogenéticos e de previsão de recursos minerais; Folhas SD-24-Y-B, Ilhéus e SD-24Z-A, Itacaré, Escala 1:250.000. Salvador: CPRM, $2 v$.

OLIVEIRA, J.E.; BARBOSA, J.S.F.; ARCANJO, J.B.A. (1993) Petrografia e petroquímica dos granulitos da região de Itabuna, Bahia. Revista de Brasileira de Geociências, v.23, n.4, p.356-369.

OLIVEIRA, E.P.; LIMA, M.I.C. (1982) Aspectos petroquímicos das rochas granulíticas do Complexo Jequié e estimativas das condições fisicas do metamorfismo. In: CONGRESSO BRASILEIRO DE GEOLOGIA, 32 ., Salvador, 1982. Anais. Salvador, SBG. v.2. p.589-602. 
OLIVEIRA, E.P.; LIMA, M.I.C.; CARMO, U.F. (1982) The archean granulites terrains from east Brazil. Revista Brasileira de Geociências, v. 12, n. $1 / 3$, p. 356-368.

PADILHA, A.V.; SANTOS, R.A.; MARTINS, A.A.M.; ARCANJO, J.B.A.; OLIVEIRA, J.E.; GOMES, R.A.A.D. (1990) O ciclo Jequié no sudeste da Bahia: uma colisão arco de ilhas - continente no Arqueano Superior. In: CONGRESSO BRASILEIRO DE GEOLOGIA, 36., Natal, 1990. Boletim de Resumos. Natal, SBG. v.1. p. 345 .

PEDREIRA, A.J. (1976) Carta geológica do Brasil ao Milionésimo: folha Salvador (SD-24) - texto explicativo. Brasília, DNPM. 127p.

PEDREIRA, A.J.; OLIVEIRA, J.E; SILVA, B.C.E. (1975) Projeto Bahia: geologia da bacia do rio de Contas. Salvador, CPRM. v.3. 345p. (Relatório Final)

RAMSAY, J.G. (1967) Folding and fracturing of rocks. McGraw-Hill. $568 \mathrm{p}$.

SÁ, J.H.S.; BARBOSA, J.S.F. (1990) Origem dos depósitos de barita de Pirai do Norte. In: CONGRESSO BRASILEIRO DE GEOLOGIA, 36., Natal, 1990. Boletim e Breves Comununicações. Natal, SBG. p.122.

SIGHINOLFI, G.P. (1970) Investigation into the deep levels of the continental crust; petrology and chemistry of granulites facies terrains of Bahia (Brazil). Atti de la Societa Toscana Science Naturelle Memoire. Série A., v. 77 , p. 327-341.

SIGHINOLFI, G.P. (1971) Investigation into deep crustal levels: fractionating effects and geochemical trends related to high-grade metamorphism. Geochimica et Cosmochimica Acta, v.35, p.1005-1021. SIGHINOLFI, G.P.; FIGUEIREDO, M.C.M.; FYFE, W.S.; TANNER DE
OLIVEIRA, M.A. (1981) Geochemistry and petrology of the Jequié Granulitic Complex (Brazil). Contributions to Mineralogy and Petrology, v.78, p.263-271.

SILVA FILHO, M.A.; MORAES FILHO, O.; GIL, L.A.A. (1974) Projeto Sul da Bahia: geologia da Folha SD-24-Y-D - relatório final. Salvador, CPRM/DNPM. v.1,238p.

SILVA, L.C. (1991) Geoquímica, petrologia e evolução dos granulitos depletados e não depletados da Bahia. Brasília, 143p. (Dissertação Mestrado) - Instituto de Geociências, Universidade de Brasilia.

SILVA, M.G.; BARBOSA, J.S.F.; MISI, A. (1992) A Faixa Aratuípe Nova Canaã: um trend de corpos máficos e ultramáficos de grande potencial metalogenético no Cinturão Granulítico Jequié-Itabuna (BA). In: CONGRESSO BRASILEIRO DE GEOLOGIA, 37., São Paulo, 1992. Boletim de Resumos Expandidos. São Paulo, SBG. v.2. p.227228.

SIQUEIRA, L.P. (1978) A evolução geológica do precambriano no Estado da Bahia e as mineralizações. In: CONGRESSO BRASILEIRO DE GEOLOGIA, 30., Recife, 1978. Anais. Recife, SBG. v.6, p.24782492.

XAVIER, R.P.; BARBOSA, J.S.F.; IYER, S.S.; CHOUDHURI, A.; VALARELLI, J.V. (1989) Low density carbonic fluids in the Archean granulite facies terrains of the Jequié Complex, Bahia, Brazil. Journal of Geology, v.97, p.351-359.

WILSON, N. (1987) Combined Sm$\mathrm{Nd}, \mathrm{Pb} / \mathrm{Pb}$ and $\mathrm{Rb}-\mathrm{Sr}$ geochronology and isotope geochemistry in polymetamorphic precambrian terrains: examples from Bahia Brazil and Channel Island U.K. Oxford, 150p. (Dissertação - Mestrado) - Oxford University. 
WILSON, N.; MOORBATH, S.; TAYLOR, P.N.; BARBOSA, J.S.F. (1988) Archean and early proterozoic crustal evolution in the São
Francisco Craton, Bahia, Brazil. Chemical Geology, v.70, n.1/2, p.146.

J.B.A.Arcanjo - CPRM - Companhia de Pesquisa de Recursos Minerais, Estrada da Suçuarana, 2862, CEP 41250, Salvador, BA, Brasil. 